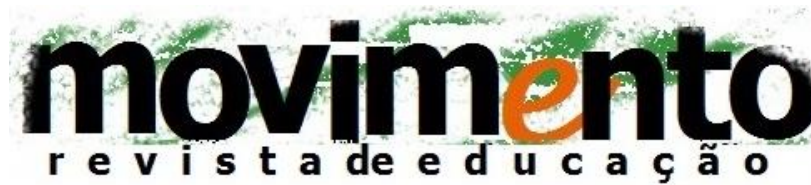

faculdade de educação - programa de pós-graduação em educação

universidade federal fluminense

issn 2359-3296

ano 3 número 4 - 2016

\section{POLÍTICA DE FORMAÇÃO PARA JOVENS E ADULTOS TRABALHADORES: O currículo do Programa Nova EJA para o ensino de física no Estado do Rio de Janeiro}

Sandro dos Santos Pinto ${ }^{1}$

\section{RESUMO}

No presente artigo, analisamos possíveis sentidos sobre formação humana, no âmbito do currículo destinado ao ensino de Física, no Programa Nova EJA (NEJA), implementado em 2013 para a modalidade de Educação de Jovens e Adultos (EJA) nas escolas públicas da rede estadual do Rio de Janeiro. Do ponto de vista teóricoepistêmico, nos referenciamos à perspectiva histórico-ontológica (Saviani e Duarte, 2010) da formação humana, enquanto princípio educativo (Gramsci, 2014), no ensino de Física do programa em referência. A partir do método do materialismo históricodialético e da compreensão da linguagem enquanto produção ideológica (Bakhtin, 2006), procedemos à análise dos documentos do programa e do material didático para o ensino de Física. Os resultados da pesquisa nos indicaram, entre outros, uma forte de tendência de resumir o ensino de Física à resolução de problemas matemáticos com frágil vinculação aos chamados conteúdos físicos. A pesquisa também evidenciou que a presença de professores sem formação na licenciatura de Física, nos quadros do Nova EJA, favorece ao reducionismo do ensino da Física, por sua ênfase na resolução de problemas sem diálogo com a prática social de jovens e adultos, o que pode comprometer 0 processo formativo destes sujeitos na sua relação com os conhecimentos físicos socialmente produzidos. Essa tendência se agrava, quando se consideram os entraves presentes no material didático, no que tange à sua qualidade $e$ à falta de vínculos com a prática social do estudante da EJA.

Palavras-chave: Formação humana, Programa Nova EJA, Currículo de Física.

\footnotetext{
${ }^{1}$ Mestrando em Educação (UERJ). Professor de Física da Secretaria de Estado de Educação do Rio de Janeiro (SEEDUC) e da Fundação de Apoio à Escola Técnica do Estado do Rio de Janeiro (FAETEC)
} 


\begin{abstract}
In this article, we analyze possible senses of human development within the curriculum for the teaching of physics in the Nova EJA program, implemented in 2013 to the Youth and Adult Education in the public schools of the state of Rio de Janeiro. From the theoretical and epistemological point of view, we reference in the historical and ontological perspective (Saviani and Duarte, 2010) of human formation, as educational principle (Gramsci, 2014), in the teaching physics of the program in reference. From the method of historical and dialectical materialism and understanding of language as ideological production (Bakhtin, 2006), we analyzed the program documents and educational materials for teaching physics. The results indicated in, among others, a strong tendency to summarize the teaching of Physics to solve mathematical problems with weak ties to so-called physical content. The results also showed that the presence of untrained teachers of Physics, in the Nova EJA program, favors the reductionism of teaching physics, for its emphasis on problem solving without dialogue with the social practice of young people and adults, which can prejudice the formation process of these subjects in their relation to the physical knowledge socially produced. This tendency is aggravated when considering the obstacles present in the teaching material, with respect to its quality and lack of ties to the social practice of youth and adult student.
\end{abstract}

Keywords: Human formation. Nova EJA program. Curriculum Physics.

\title{
INTRODUÇÃO
}

O artigo é fruto de uma dissertação de mestrado concluída em 2016 e busca contribuir para o debate acerca das políticas públicas em educação, em específico para as políticas de currículo no Ensino Médio, na modalidade da Educação de Jovens e Adultos (EJA). A pesquisa teve como objeto o Ensino de Física no currículo do Programa Nova EJA (NEJA), programa este implantado em 2013 nas escolas da rede pública do estado do Rio de Janeiro.

A literatura no campo da educação de jovens e adultos trabalhador tem confirmado o seu caráter classista, na medida em que a oferta para essa modalidade de ensino configura a possibilidade de elevação da escolaridade para os que tiveram negado o seu direto à educação na fase da vida considerada adequada. Trata-se de uma educação para as frações da classe trabalhadora que desempenham papéis no cenário produtivo que não demandam maiores investimentos do Estado (Rummert, 2007; Machado, 2013; Alvarenga, 2015). Integra a este caráter, a tendência do aprofundamento da fragmentação das 
políticas destinadas à modalidade, reiterando sua natureza efêmera e compensatória.

Considerado este contexto, nos perguntamos: quais são (im) possibilidades formativas do programa Nova EJA, sob a perspectiva da formação humana enquanto princípio educativo, no ensino de Física? O currículo do NEJA traz de fato algo "novo" para a formação dos alunos trabalhadores, em particular no ensino de Física?

A partir destas questões, organizamos o artigo em duas seções. Na primeira seção, contextualizamos o Programa Nova EJA como parte da totalidade das políticas públicas para a educação. Na segunda, em diálogo com os referenciais teórico-metodológicos da pesquisa, procedemos a duas frentes de análise das fontes que constituem o corpus documental. A primeira consiste na análise do Relatório de Gestão e Políticas Públicas de 2014 (Rio de Janeiro, 2014a, 2014b); a segunda, consiste na análise do manual de orientações do programa (Rio de Janeiro, 2015) e do material didático destinado ao ensino de Física (manuais do professor e livros do aluno). Secundariamente, foram realizadas entrevistas com docentes de Física do programa, numa escola pública, no município de Itaboraí, na região metropolitana do Rio de Janeiro. Tínhamos como objetivo analisar os sentidos produzidos a respeito do material didático, do programa Nova EJA e do ensino de Física na modalidade. Tais sentidos constituem elementos de cotejamento na análise dos documentos e livros.

É importante destacar que, condizentes com os princípios do materialismo histórico-dialético, entendemos que os documentos oficiais, o material didático e as falas dos docentes constituem material enunciativo (Bakhtin, 2006). Adotamos, assim, a abordagem que toma a linguagem em sua natureza ideológica, expressão da totalidade da vida.

Nas considerações finais, sinalizamos que a pesquisa evidenciou que a presença de professores sem formação na licenciatura de Física, nos quadros 
do NEJA, favorece ao reducionismo do ensino da Física à mera resolução de problemas, sem diálogo com a prática social de jovens e adultos, o que pode comprometer o processo formativo destes sujeitos na sua relação com os conhecimentos físicos socialmente produzidos. Essa tendência se agrava, quando se consideram os entraves presentes no material didático, no que tange à sua qualidade e à falta de vínculos com a prática social do estudante da EJA. Vale assinalar que na revisão de literatura, realizada a partir da consulta ao banco de teses da CAPES, dos trabalhos apresentados nas reuniões da Associação Nacional de Pós-Graduação e Pesquisa em Educação (ANPED), entre 2010 e 2015, e na reunião da ANPED Sudeste de 2014, não identificamos nenhum trabalho que tivesse o programa como objeto de estudo.

Ainda, tendo em vista o levantamento dos trabalhos apresentados no Simpósio Nacional de Ensino de Física (SNEF)², entre 2010 e 2015, concluímos haver a escassez de estudos destinados à EJA, às políticas curriculares para a modalidade e a ausência de discussões sobre a programa Nova EJA, indicando uma lacuna importante na qual o presente artigo pode dar sua contribuição, na interface entre políticas públicas para EJA, formação humana e currículo de Física.

\section{Contextualizando o Programa Nova EJa}

Quais as determinações incidem sobre o programa Nova EJA, considerando a totalidade das políticas públicas para a educação? O que os diversos autores críticos têm concluído a respeito das políticas públicas destinadas aos estudantes jovens e adultos trabalhadores? Quais elementos podem ser

\footnotetext{
2 Os SNEFs congregam alunos e professores dos diversos níveis de ensino, interessados em debater questões relacionadas ao ensino e aprendizagem de Física, à pesquisa realizada no campo de investigação do Ensino de Física e à formação de profissionais para atuarem nesse campo, quer como docentes ou como pesquisadores. É um evento promovido pela Sociedade Brasileira de Física - SBF, e que acontece a cada dois anos, mudando a cidade-sede a cada simpósio.
} 
depreendidos desses trabalhos que podem nos ajudar a compreender a totalidade da qual o NEJA é parte e participante?

Juntamente com Höfling (2001), entendemos políticas públicas como o Estado em ação. Conforme diz a autora, a política pública "é o Estado implantando um projeto de governo através de programas, de ações voltadas para setores específicos da sociedade" (p.31). Contudo, as intervenções na sociedade estão sempre vinculadas a concepções de Estado e de sociedade, de forma que podemos entender a formulação de políticas públicas como uma arena de embates pela hegemonia de sentidos.

Em seu trabalho, a autora se propõe a tensionar duas visões distintas de Estado e sociedade, a marxista e a neoliberal. No enfoque marxista tais políticas são apreendidas como mediações relacionadas tanto às necessidades da manutenção das estruturas sociais capitalistas e a resolução das crises engendradas pelo capitalismo, quanto àquelas relacionadas aos conflitos de classe frente às exigências da classe trabalhadora. Desta forma, as políticas públicas servem para fins de integração social e de elaboração política das crises do processo de acumulação do capital.

Aqui vale relembrar que o papel do Brasil na divisão internacional do trabalho não demanda de fato ampla formação voltada ao trabalho complexo, muito pelo contrário, a parca qualificação para o trabalho simples faz mais sentido dentro do quadro no qual se estabelece uma cultura de cópias de tecnologias, pouco investimento em inovação tecnológica e produção científica (Oliveira, 2003). Soma-se a isso o fato de que um dos grandes atrativos aos investidores internacionais é o custo irrisório da mão-de-obra (Paulani, 2006). Isso traz determinações importantes no que diz respeito ao tipo de educação funcional à posição do país no capitalismo mundial.

De acordo com Shiroma, Moraes e Evangelista (2011), as políticas educacionais a partir dos anos 90 vêm sofrendo forte influência de diversos organismos 
multilaterais, designados pelas autoras como "os arautos da reforma educacional", cujas orientações serviram de sedimentos para políticas educacionais enformadas pelo pensamento neoliberal no Brasil. Em linhas gerais, os documentos produzidos por tais organismos disseminaram uma concepção de educação fortemente vinculada à preparação para o mercado do trabalho, recapitulando a noção de capital humano, segundo a qual um incremento educacional equivaleria a melhores oportunidades econômicas. As autoras afirmam que os documentos ${ }^{3}$ entendem a educação com um viés salvacionista, como se a ela coubesse a redenção das mais diversas mazelas sociais. Percebe-se uma preocupação acentuada a respeito da adequação da educação com as mudanças no mundo produtivo e a necessidade de se desenvolver habilidades e competências para os novos tempos. Ganham destaque o dito desenvolvimento sustentável, tanto para o crescimento econômico como para a justiça, equidade e paz social. A questão da pobreza é vista como passível de ser atenuada através de uma formação fincada em valores como solidariedade, capacidade de iniciativa, autonomia, tendo em vista o envolvimento das pessoas na resolução dos problemas de sua comunidade.

Torres (1998) dá enfoque às estratégias das políticas neoliberais orientadas pelo Banco Mundial (BM) para a melhoria da qualidade da educação básica. A autora considera a posição de destaque que o BM assumiu nas últimas décadas do século passado ocupando a posição tradicional da UNESCO. Ainda assinala que o financiamento não tem sido o único e o mais importante papel do BM na educação, antes tem figurado como a principal agência de assistência técnica em matéria educacional para os países em desenvolvimento. Nos termos do BM: "no plano internacional, o Banco é a maior fonte de assessoria em matéria de

\footnotetext{
${ }^{3}$ Os documentos destacados pelas autoras são: a declaração resultante da Conferência Mundial de Educação para Todos, realizada em Jomtien, Tailândia, em 1990, esta financiada pela UNESCO (Organização das Nações Unidas para a Educação, a Ciência e a Cultura), UNICEF (Fundo as Nações Unidas para a Infância), PNUD (Programa das Nações Unidas para o Desenvolvimento) e Banco Mundial; o documento econômico da CEPAL (Comissão Econômica para a América Latina e Caribe) Transformación productiva con equidade, de 1990; o relatório Delors, documento produzido pela UNESCO entre 1993 e 1996; as diretrizes aprovadas pelo Comitê Regional Intergovernamental em 1993, conhecidas como PROMEDLAC (Proyeto Principal de Educación em América Latina y Caribe) V; e o documento Prioridades y estrategias para la educación, publicado em 1995, pelo Banco Mundial.
} 
política educacional e de fundos externos para esse setor" (Banco Mundial, 1992: 7 apud Torres, 1998).

O enfoque do BM em educação é recente e, nesse sentido, um marco importante se deu em 1973, quando o então presidente Robert Mcnamara anunciou que o banco focalizaria sua ação nos mais pobres, atendendo as suas necessidades de moradia, saúde, alimentação, água e educação. Neste último aspecto, as ações do banco se traduziriam numa priorização do ensino fundamental como alicerce da estratégia para redução da pobreza. Essa estratégia se viu reforçada com a Conferência Mundial sobre Educação para Todos, em 1990, que definiu a educação básica como a prioridade para a década e a educação fundamental como peça chave. Para o BM, a educação básica

[...] proporciona o conhecimento, as habilidades, as atitudes essenciais para funcionar de maneira efetiva na sociedade sendo, portanto, uma prioridade em todos os lugares. Esses atributos incluem um nível básico de competência em áreas gerais tais como habilidades verbais, computacionais, comunicacionais, e a resolução de problemas. Essas competências podem ser aplicadas a uma grande variedade de empregos e permitir às pessoas adquirir habilidades e conhecimentos específicos orientados para o trabalho, quando estiverem em local de trabalho. Em geral, esse nível básico inclui cerca de oito anos de escolaridade. De fato, em muitos países, o primeiro ciclo da educação secundária está sendo combinado coma e educação de primeiro grau para conformar uma etapa obrigatória conhecida como "educação básica" (Banco Mundial, 1995, apud TORRES, 1998, grifo nosso).

Nesse excerto fica clara a defesa por uma educação funcionalista que visa integrar o estudante à sociedade, mantendo intocáveis suas estruturas. O papel de escola seria o de desenvolver as competências necessárias ao mercado de trabalho, no qual o aluno, após sua passagem pelo sistema formal de ensino, seria integrado.

A análise de Torres (1998) centra-se no documento Priorities and strategies for education: a World Bank sector review, de 1995, mas também considera documentos anteriores publicados pelo BM. Destacamos dentre os elementos distintivos no "pacote" para os países em desenvolvimento a melhoria da 
qualidade (e da eficiência) da educação, que é tomada como eixo da reforma educativa. A lógica que perpassa o documento é a econômica, sendo as categorias centrais a relação custo-benefício e a taxa de retorno. É a partir delas que prioridades educacionais são hierarquizadas; é sobre esses marcos que a educação passa ser pensada.

O ensino e aprendizagem são entendido em termos mecânicos e como fatores estanques, em vez de um processo complexo, sistêmico. A autora afirma que para o BM o ensino:

[...] resume-se a um conjunto de insumos (inputs) que intervêm na caixa preta da sala de aula - o professor sendo mais um insumo - e a aprendizagem é vista como o resultado previsível da presença (e eventual combinação) desses insumos. Cada insumo se valoriza em separado e é priorizado ou não em virtude de duas questões: sua incidência sobre a aprendizagem (segundo estudos empíricos que mostrariam tal incidência) e seu custo. (Torres, 1998, p. 140).

Sob essa lógica são delineados um conjunto de "avenidas promissoras" e "becos sem saída". São sugeridas medidas de alta incidência e baixo custo (caso do livro didático) e desestimulam-se aquelas de baixa incidência e baixo custo (caso dos docentes).

Ao analisar a concepção de currículo subjacente à proposta do BM, Torres conclui ser estreita, pelo fato de reduzir as concepções amplas de currículo (que abarcam os conteúdos, os objetivos, as estratégias, os métodos, os materiais de ensino, os critérios e método de avaliação) a conteúdos a serem transmitidos pelos professores e assimilados pelos alunos, bem como quais habilidades são pertinentes - aquelas predominantemente orientadas ao mercado de trabalho.

Essa perspectiva é coerente com a sugestão de se realizar a reforma curricular via livro didático, sem levar em conta, por exemplo, a centralidade do professor na produção do currículo efetivo. Afinal, pela lógica do custo-benefício é mais interessante o investimento em livro didático do que em formação docente. Além disso, tal reforma do currículo segue um modus operandi vertical, de cima para baixo, realizado sem participação dos envolvidos na efetivação do currículo, 
elitista, no qual prevalece a lógica econômica de curto prazo. Nesse sentido, a autora adverte que uma reforma curricular

[...] não é um documento, nem um decreto, nem um fato meramente escolar, mas um processo social, de mudança cultural, sumamente complexo e longo que, como tal, exige o trabalho de várias frentes e em vários níveis e, sobretudo, [...] não há possibilidade de por em prática [...] sem colocar no centro o professor (Torres, 1998, p.155)

Por outro lado, a opção pelo livro didático como currículo efetivo repousa na ideia de se oferecer um receituário, um texto programado, fechado e normativo, que oriente o docente em sua prática, pretendendo antecipar as respostas aos alunos e professores - como se a realidade complexa e a diversidade de situações escolares pudessem ser apreciadas em sua totalidade por alguma obra. Superestima-se, assim, o papel do livro didático: de um elemento importante no currículo efetivo ele passa a ser tomado como o currículo em si.

Condizente com as orientações do BM, as políticas educacionais têm apresentado um caráter descentralizador, ao se realizarem a partir de contratos entre União, Estados e Municípios, além das parcerias com instituições da sociedade civil e ONGs. Dessa forma, o Estado tende a se eximir de suas responsabilidades e pulveriza suas obrigações com outros atores, ao mesmo tempo em que exerce seu controle sobre pontos estratégicos, através de relatórios e avaliações externas.

\section{O Programa Nova EJA sob a análise da Pedagogia Histórico-Crítica}

Diversos autores têm se desdobrado em analisar a formação escolar numa perspectiva crítica, ou seja, considerando os vínculos entre escola e sociedade. Alguns deles enfatizaram a reprodução das classes sociais nas escolas capitalistas. Já outros autores realizaram análises que recaem sobre as possíveis de maneiras de se articular escola com a transformação social. Uma teoria pedagógica que corrobora com essa última perspectiva é a Pedagogia Histórico-Crítica (Saviani, 2011, 2012; Libâneo, 2012). 
A Pedagogia Histórico-Crítica foi desenvolvida nos fins dos anos 70 como crítica às concepções crítico-reprodutivistas da educação que, de certa maneira, limitavam as possibilidades de se vislumbrar mudanças na sociedade a partir da escola. A despeito das importantes contribuições das teorias reprodutivistas, ao explicitarem as diversas maneiras através das quais a escola perpetua a estrutura social capitalista, tais perspectivas abordam os vínculos entre educação e sociedade de forma linear e mecânica, deixando de contemplar suas contradições e sua natureza dialética. É nesse contexto que se desenvolve a Pedagogia Histórico-Crítica que pretende colaborar para a transformação social a partir da escola concreta, que abarca aspectos de conformação e de superação à ordem estabelecida.

A concepção pressuposta dessa pedagogia é a do materialismo histórico, ou seja, a compreensão da história a partir do desenvolvimento material e de suas determinações à existência humana. Nessa perspectiva pedagógica, os conteúdos escolares figuram como centrais por serem a materialidade através da qual os alunos poderiam desenvolver uma concepção histórica e dialética da realidade.

Por conta deste enfoque, pode-se pensar que se trata de uma defesa à pedagogia tradicional e conteudista. Todavia, trata-se de argumentar a favor de uma escola cuja função principal seria a transmissão de saberes sistematizados, e cujo ensino se daria a partir da vida do aluno, de sua prática social. Esse ponto de partida está relacionado a uma visão sincrética e fragmentada do mundo por parte do estudante. Caberia ao professor mediar o aluno ao conhecimento escolar, de forma a aproximá-lo de uma visão sintética da realidade, permitindoo perceber a unidade na diversidade. Daí a Pedagogia Histórico-Crítica não se opor às disciplinas escolares - desde que não sejam entendidas como elementos autônomos e destacados da totalidade do conhecimento humano e de sua produção. 
Esta perspectiva pedagógica nos traz elementos importantes para avaliarmos a que formação humana o ensino de Física, enformado pelo respectivo currículo, no programa Nova EJA, se orienta.

2.1 Relatório de Gestão e Políticas Públicas da Secretaria Estadual de Educação

O Programa Nova EJA, elaborado em parceria com a Fundação Centro de Ciências e Educação Superior à Distância do Estado do Rio de Janeiro (CECIERJ), foi implantado pela resolução SEEDUC № 4951 de 04 de outubro de 2013, capítulo VI (Da Educação de Jovens e Adultos), nos artigos 31 e 32, sendo identificado inicialmente como Projeto Nova EJA Ensino Médio. Ele é destinado a todas as escolas públicas que ofertam EJA nível médio, no Estado do Rio de Janeiro.

A carga horária diária do programa, em comparação aos moldes anteriores a 2013, foi reduzida de seis para quatro tempos (em 1/3), mas em compensação a duração do curso foi ampliada de no mínimo três etapas semestrais para quatro etapas semestrais. Por dia, o aluno tem três horas e vinte minutos de aula, de segunda à sexta-feira.

O programa tem material didático próprio, tanto para a formação continuada dos docentes como para os alunos. No que diz respeito à formação continuada, acontece concomitante à atuação nas turmas de EJA, na modalidade semipresencial, isto é, com atividades presenciais e à distância.

Dentre os documentos oficiais que orientam o programa, temos o Relatório de Gestão e Políticas Públicas de 2014 (Rio de Janeiro, 2014a, 2014b), elaborado na gestão do Governador Luiz Fernando Pezão, com o economista Wilson Risolia na função de Secretário de Estado de Educação. O relatório, segundo a SEEDUC, é um esforço em prol da transparência enquanto um dos pilares da administração pública. Assim, o documento objetiva apresentar de forma sistemática as ações realizadas na rede estadual, no âmbito educacional. Ações estas elaboradas a partir do planejamento estratégico formulado no último 
semestre de 2010, vigente até a data de publicação do relatório. Segundo a SEEDUC, o planejamento teve como motivação principal a melhoria da aprendizagem dos alunos e, a partir disso, são elencados a missão, a visão e os valores da instituição, aos moldes empresariais (Rio de Janeiro, 2014a, p.7). Fica explícita a escolha da SEEDUC por valores hegemônicos dentro das políticas públicas recentes no âmbito da educação, caracterizadas pela ênfase na eficiência econômica, na gestão empresarial e na meritocracia.

De acordo com o relatório, o NEJA constitui uma das ações para a resolução da elevada distorção idade-série da rede estadual. O documento atrela a distorção idade-série às diversas questões envolvidas na baixa qualidade de educação na rede pública estadual de ensino. Ganha centralidade o problema da pouca profissionalização da gestão escolar, e dele irradiam outras questões: baixo rendimento dos alunos e falta de interesse pela escola; docentes e servidores desestimulados; baixo investimento e ineficiência do gasto; ruídos de comunicação e pouca transparência. No âmbito do baixo rendimento dos estudantes, destacam-se: falta de instrumento diagnóstico; falta de alinhamento ao currículo; aulas com baixa atratividade; alunos com dificuldade de aprendizagem; e elevada distorção idade-série.

Vale lembrar que dentre as diversas orientações dos organismos multilaterais para o âmbito educacional, podemos destacar aquelas advindas da preocupação com o gasto excessivo do sistema educacional, em especial com aqueles alunos que ficam tempo além do previsto para um percurso escolar adequado. Desta maneira, diversas têm sido as ações nos estado e municípios que incidem sobre a questão do fluxo escolar (Figueiredo, 2009; Freitas et al., 2013; Souza et al. 2011). A distorção idade-série tem se apresentado como um problema importante no Plano Nacional de Educação 2001-2010 e no PNE atual.

O documento mais elucidativo a respeito da Nova EJA é o manual de orientações do programa (Rio de Janeiro, 2015). Em suas páginas 12 e 13 encontramos a proposta de organização curricular do programa em módulos semestrais: 
Quadro 1 - Organização curricular do programa Nova EJA

\begin{tabular}{c|c|c} 
Disciplina & Tempos semanais & Total \\
\hline \multicolumn{2}{c}{ Módulo I } \\
\hline Língua Portuguesa/Literatura I & 4 & 80 \\
\hline Matemática I & 4 & 80 \\
\hline História I & 4 & 80 \\
\hline Geografia I & 4 & 80 \\
\hline Filosofia I & 2 & 40 \\
\hline Sociologia I & 2 & 40 \\
\hline & TOTAL & 400 \\
\hline
\end{tabular}

Módulo II

\begin{tabular}{c|c|c}
\hline Língua Portuguesa/Literatura II & 4 & 80 \\
\hline Matemática II & 4 & 80 \\
\hline Química I & 4 & 80 \\
\hline Física I & 4 & 80 \\
\hline Biologia I & 2 & 40 \\
\hline & TOTAL & 400 \\
\hline
\end{tabular}

Módulo III

\begin{tabular}{c|c|c}
\hline Língua Portuguesa/Literatura III & 4 & 80 \\
\hline Matemática III & 4 & 80 \\
\hline História II & 3 & 60 \\
\hline Geografia II & 3 & 60 \\
\hline Filosofia II & 2 & 40 \\
\hline Sociologia II & 2 & 40 \\
\hline Educação Física & 2 & 40 \\
\hline & TOTAL & 400 \\
\hline
\end{tabular}

Módulo IV

\begin{tabular}{c|c|c}
\hline Língua Portuguesa/Literatura IV & 4 & 80 \\
\hline Matemática IV & 4 & 80 \\
\hline Física II & 3 & 60 \\
\hline Química II & 3 & 60 \\
\hline Biologia II & 3 & 60 \\
\hline Língua estrangeira & 2 & 40
\end{tabular}




\begin{tabular}{c|c|c} 
Artes & 2 & 40 \\
\hline & TOTAL & 400
\end{tabular}

Notamos que o currículo do NEJA intercala as Ciências Humanas com as da Natureza, tendo Língua Portuguesa/Literatura e Matemática em todos os módulos. Além disso, em comparação à organização curricular da EJA anterior a 2013, quando aos alunos eram ofertadas cerca de 10 disciplinas por semestre, observamos uma menor fragmentação dentro do mesmo período, possibilitando maior tempo de interação entre estudantes e docentes no módulo. Nesse quadro, a disciplina Física é oferecida no módulo 2, com 4 tempos semanais; e no módulo 4, com 3 tempos semanais.

A inserção do professor no programa é feita através do processo de adesão, sendo obrigatória a sua participação nas formações em dois módulos, na mesma disciplina. A formação continuada para os professores, que acontece concomitante à atuação em sala de aula, na modalidade semipresencial. O curso percorre o material didático do aluno e pretende fomentar a criação de novas práticas pedagógicas entre os professores.

A partir das metas destinada a estudantes e docentes, presentes na página 6 do manual, fica notória a preocupação de se formar um trabalhador condizente com as ditas demandas sociais do século XXI, conformando-o à estrutura social estabelecida, tendo vista a importância dada ao desenvolvimento da autorregulação, de habilidades e competências para o mundo do trabalho e social, de formar hábitos consistentes, de normas de convivência, da autonomia para aprender ao longo da vida. Esses objetivos se aproximam das teses do capital humano e da pedagogia das competências (Ramos, 2002) que, no plano pedagógico, estabelece a passagem de um ensino centrado em saberes disciplinares a um ensino definido pela produção de competência verificáveis em situações e tarefas específicas. Desta forma, os conteúdos das disciplinas passam a ficar em segundo plano, sendo evocados quando necessários a situações concretas particulares. 
Segundo o manual, historicamente, a Educação de Jovens e Adultos, "constitui um desafio para a gestão educacional" (Rio de Janeiro, 2015, p.4). Situa-se, desta forma, a questão da baixa qualidade da educação oferecida na EJA dentro de um escopo gerencial, a despeito das determinações histórico-sociais. Toda a problemática da EJA é resumida a um problema de gestão, a uma questão técnica.

2.2. O currículo no Ensino da Física no Programa Nova EJA em seu material didático

O material didático do NEJA constitui-se de um conjunto de livros do aluno (Rio de Janeiro, 2013a, 2013b, 2013c, 2013d) e material de professor ${ }^{4}$. Para o aluno, são disponibilizados quatro volumes; cada um deles aborda as Ciências da Natureza (Física, Química e Biologia). São dois volumes para o módulo 2 e mais dois para o módulo 4.

O material destinado ao professor consiste num conjunto de quatro livros, um para cada volume do material dos alunos. A correspondência segue também no que diz respeito à organização das unidades. São apresentados diversos recursos e ideias para que o enriquecimento das práticas pedagógicas. Assim, são sugeridas diversas atividades que se organizam, grosso modo, como atividades em grupos ou individuais (apresentação de vídeos, realização de demonstrações, experimentos feitos com recursos simples disponíveis); uso de applets (programas que precisam ser instalados em computadores ou smartphones); avaliativas (questões ou propostas de avaliação); e aplicação de exercícios complementares. Há ainda um CD com conteúdo multimídia para os docentes.

De forma geral, é possível concluir que as atividades propostas e as orientações de implementação são positivas e com bom nível de detalhamento,

\footnotetext{
${ }^{4}$ Disponível em: <http://projetoseeduc.cecierj.edu.br/eja-material-professor.php>. Acesso em: 04 maio 2016.
} 
possibilitando ao professor sua execução sem grandes contratempos. Contudo, vale assinalar, as atividades são orientadas por objetivos conteudistas, sem fazer relação com a realidade dos estudantes.

$\mathrm{Na}$ análise que segue damos ênfase ao material destinado ao aluno. Damos destaque a alguns aspectos que julgamos pertinentes à percepção das intenções formativas que subjazem o material didático. Fomos, de certa maneira, inspirados por trabalhos dão ênfase à ideologia presente no livro didático (Faria, 2000), à interdisciplinaridade, ao fomento do diálogo entre estudante e professor, aos sujeitos envolvidos na confecção do material didático e à adequação do material aos sujeitos jovens e adultos (Fávero e Santos, 2011). Buscamos por em evidência elementos que nos delineie a que tipo de formação o livro didático e o do professor está a serviço, levando em conta, especialmente, as contribuições da Pedagogia Histórico-Crítica.

\section{- A ênfase na quantidade em detrimento da qualidade}

Um dado que nos salta os olhos é o volume de conteúdos destinado ao ensino de Física e o pouco tempo de encontro disponibilizado pelo programa, sendo um indício do aligeiramento do ensino, posição esta sinalizada em uma entrevista: "A quantidade de matéria que o livro trazia demonstrava uma posição extremamente otimista do autor. Era impossível trabalhar o conteúdo todo". Identificamos um total de 556 páginas destinadas ao ensino de Física. A título de comparação, segundo o edital do Programa Nacional do Livro Didático (PNLD) para a EJA 20145, o número máximo de páginas para o material didático do aluno correspondente a todo o ensino médio, é de 1536 páginas para 4 disciplinas: Matemática, Química, Física e Biologia. No programa Nova EJA, somente para Química, Física e Biologia, são destinadas 1924 páginas, a serem trabalhadas em apenas dois semestres!

\footnotetext{
${ }^{5}$ Disponível em: <http://www.fnde.gov.br/arquivos/category/165-editais?download=7534:pnld2014-eja>. Acesso em: 04 maio 2014.
} 
Ao longo da leitura dos livros, percebe-se um grande descaso na forma da apresentação. É como se o direito do estudante em ter acesso aos conhecimentos físicos fosse meramente formal, e não incluísse o direito à forma adequada de serem apresentados. Não nos detivemos numa análise mais detalhada das possíveis inconsistências conceituais, usos inadequados da língua portuguesa, equívocos nas referências internas (equações, figuras, esquemas), apesar de alguns erros nos saltarem aos olhos e serem impossíveis de serem ignorados e, do nosso ponto de vista, suficientes para justificar nossa conclusão. A quantidade de erros é tão grande que uma ou duas leituras do material já seriam suficientes para deixar claro o desleixo da edição. Um dos professores entrevistados já nos alertava para as dificuldades em relação à linguagem utilizada no livro que, para ele, deve-se à postural excessivamente formal do texto.

O material, o livro era bem explicado às vezes, muitas vezes se embolava um pouco na explicação e tinha que dar um jeitinho. [...] A linguagem era um ponto negativo, muitas vezes se afastava da linguagem do aluno [...] A linguagem do conteúdo poderia ser um pouco melhor trabalhada. Muito formal. Tô trabalhando com pessoas que deixaram de, de falar, deixaram de estudar durante algum tempo e que desacostumaram com aquele português de livro, vamos dizer assim.

Concordamos com o professor e na verdade essa formalidade se desdobra em deduções matemáticas complicadas. Contraditoriamente, esse rigor matemático vem acompanhado muitas vezes do uso inconsistente de variáveis, tornando extremamente difícil a compreensão das deduções, em especial àqueles que não têm familiaridade com a linguagem matemática. No quadro a seguir, tentamos organizar os principais equívocos do livro didático do aluno fazendo menção a alguns exemplos.

Quadro 2 - Quadro dos erros presentes no material didático de Física

\begin{tabular}{l|l|l}
$\begin{array}{l}\text { Natureza } \\
\text { dos erros }\end{array}$ & Descrição & Exemplos
\end{tabular}




\begin{tabular}{|c|c|c|}
\hline Conceitual & $\begin{array}{l}\text { Diz respeito a definições e usos } \\
\text { equivocados de conceitos físicos. }\end{array}$ & $\begin{array}{c}\text { "Quando não são submetidos } \\
\text { a forças de natureza } \\
\text { dissipativa, esses sistemas } \\
\text { são chamados de } \\
\text { conservativos, porque } \\
\text { preservam (conservam) a } \\
\text { energia total" - Rio de } \\
\text { Janeiro, 2013b, p.160. } \\
\text { Sistemas conservativos } \\
\text { conservam a energia } \\
\text { mecânica. }\end{array}$ \\
\hline Linguagem & $\begin{array}{l}\text { Refere-se ao uso inadequado da } \\
\text { língua portuguesa: ortografia, } \\
\text { concordância etc. }\end{array}$ & $\begin{array}{c}\text { "Ainda nessa sessão [...]" - } \\
\text { Rio de Janeiro, 2013b, p } 204 . \\
\text { O correto seria seção. } \\
\text { "Suas seções não estam } \\
\text { divididas [...]" - Rio de } \\
\text { Janeiro, 2013c, p.169. O } \\
\text { correto seria estão. }\end{array}$ \\
\hline Organização & $\begin{array}{l}\text { Tem a ver com erros na estrutura e } \\
\text { forma da apresentação: } \\
\text { inconsistência no uso das seções, } \\
\text { numeração de imagens, referência } \\
\text { interna a outras seções e unidades, } \\
\text { imagens com problema de escala, } \\
\text { falta de correspondência entre texto } \\
\text { e imagem, textos muito extensos } \\
\text { que "pedem" imagens para facilitar a } \\
\text { compreensão etc. Uso de conceitos } \\
\text { que não haviam sido apresentados } \\
\text { ou que não são apresentados. }\end{array}$ & $\begin{array}{c}\text { O conceito de campo elétrico } \\
\text { é mencionado sem ser } \\
\text { explicado em nenhuma parte } \\
\text { do livro - Rio de Janeiro, } \\
2013 c, \text { p. } 185, \text { p. } 191,192 . \\
\text { O uso do subscrito é } \\
\text { inconsistente - Rio de } \\
\text { Janeiro, } 2013 d, \text { p. } 198,219, \\
220 \text {. } \\
\text { A numeração de imagens não } \\
\text { confere - Rio de Janeiro, } \\
2013 c, \text { p. } 236 \text { - } 252 .\end{array}$ \\
\hline
\end{tabular}

- Resistência à totalidade: a Física sem sociedade e sem história, ou a história e a sociedade como meros adendos

Dentro de uma perspectiva materialista, todo objeto de conhecimento é síntese de múltiplas determinações de naturezas diversas. Assim, condizente com a Pedagogia Histórico-Crítica, as disciplinas constituem parte da totalidade do conhecimento humano. São as múltiplas necessidades humanas, de ordens diversas (biológica, intelectual, estética...) que engendram a produção do conhecimento. Dessa maneira, conhecer um objeto é conhecer as relações entre ele e a totalidade. A interdisciplinaridade constitui como uma necessidade no 
processo de conhecer, seja na pesquisa ou na atividade pedagógica (Frigotto, 2008).

Isso demandaria trabalhar o conteúdo disciplinar articulado ao contexto históricosocial de sua produção, sendo, inclusive, um dos critérios de eliminação no edital do PNLD - Ensino Médio 2015. Mesmo que essa articulação não se dê em todos conceitos, seria desejável que se desse ao longo dos estudos, no mínimo em temas cuja abordagem interdisciplinar já está bem estabelecida nos diversos livros didáticos de Física. É o caso do estudo da Física térmica, que traz em seu bojo a Revolução Industrial, com seus embates e contradições. Ou ainda o caso da Gravitação Universal, fruto de diversos pensadores como Kepler, Galileu, Copérnico, Tycho Brahe; isso mencionar o legado de Ptolomeu, Aristóteles e, principalmente, os riquíssimos contextos históricos, social e político. Em relação a isso o livro faz um agudo silêncio.

No quadro que segue, apresentamos as diversas formas através das quais a história é apresentada no livro do aluno. É importante ressaltar que não estamos defendendo que as aulas de Física se tornem aulas de História ou Geografia. Mas que haja um mínimo de articulação entre a Física e as demais disciplinas de maneira mais orgânica, e não somente como enxertos.

Quadro 3 - Formas pelas o material didático relaciona a Física com a História e a sociedade

\begin{tabular}{c|c} 
Forma & Referências \\
\hline $\begin{array}{c}\text { Breve menção à história da } \\
\text { Física }\end{array}$ & $\begin{array}{c}\text { Rio de Janeiro, 2013a: Aristóteles, Galileu e } \\
\text { Anaxágora são mencionados na discussão do método } \\
\text { científico (p.163,164); Descobertas astronômicas e } \\
\text { concepção do Cosmo (Galileu, Tycho Brahe, Kepler; } p . \\
\text { 167); sobre a natureza do movimento (p.279). } \\
\text { Rio de Janeiro, 2013b: Teoria do calórico (p.231); } \\
\text { máquina térmica (p.268). }\end{array}$ \\
\hline $\begin{array}{c}\text { Breve biografia de } \\
\text { cientistas }\end{array}$ & $\begin{array}{c}\text { Rio de Janeiro, 2013b: Joule (p.143, p.232); Celsius } \\
\text { (p.208); Kelvin (p.214); Ampère (p.188); Ohm (p.194, } \\
\text { p.240). }\end{array}$ \\
\hline $\begin{array}{c}\text { Breve relação entre } \\
\text { história e sociedade; } \\
\text { enxerto sem contradição; }\end{array}$ & Rio de Janeiro, 2013b: A Termodinâmica e a \\
Revolução Industrial (p.245, p.246).
\end{tabular}


ou a ciência em nome do progresso
Rio de Janeiro, 2013c: Uso da eletricidade (p.181); Magnetismo e grandes navegações (p.265,266)

Das 566 páginas do livro do aluno, apenas 21 páginas fazem referência à história (cerca de 3,7\% da obra). Na maior parte das vezes, a história fica restrita a sucintas descrições da história das ideias da Física ou a notas biográficas, sem evidenciar os vínculos com a sociedade da época (16 páginas, $76 \%$ dos casos). Nas demais situações, quando se faz referência à sociedade, os relatos escamoteiam as contradições do desenvolvimento científico e tecnológico, enfatizando os avanços e progressos conseguidos através da Física.

No que diz respeito à relação entre Física e tecnologia, observa-se a resistência de se evidenciar seus vínculos com a sociedade. Um tema no qual comumente tais vínculos são explicitados no âmbito dos livros de Física é o da energia. Nesse contexto, tradicionalmente faz-se referência à produção de energia elétrica, pondo em evidência tanto suas formas tecnológicas (usinas hidrelétrica, termelétrica, nuclear) quando em seus aspectos sociais e ambientais. Como o livro aborda a questão da produção de energia elétrica?

São apresentados, sucintamente, os diversos tipos de usinas na subseção "Saiba mais", (Rio de Janeiro, 2013b, p.160) numa brevíssima descrição do seu funcionamento. Tendo em vista tratar-se de uma estrutura complexa, seria desejável a presença de esquemas, tão comuns nos livros didáticos de Física. Contudo, opta-se por fazer uma descrição aligeirada usando-se exclusivamente texto, dentro uma subseção que tem como intuito oferecer um aprofundamento opcional ao estudante - ou seja, trata-se de um apêndice - e nem sequer se apresenta um espaço a uma discussão dos prós e contras de cada tipo de usina.

O tema reaparece em Rio de Janeiro, 2013a, p.283, novamente na subseção "Saiba mais", tratando exclusivamente do funcionamento das usinas hidrelétricas. Agora, ao menos, o livro apresenta um esquema, todavia a sociedade continua sendo dispensável. Por exemplo, os aspectos positivos (fonte de energia renovável, aproveitamento da hidrografia brasileira) e 
negativos (alagamento da vastas regiões, impactos na fauna, flora, populações ribeirinhas) são sumariamente ignorados.

Esse tipo de abordagem se afasta radicalmente das propostas da Pedagogia Histórico-Crítica. Tendo em vista a construção de uma pedagogia articulada com os interesses dos subalternizados da sociedade, Saviani (2012) enfatiza o papel da educação escolar na luta pela transformação social. Dentro desta perspectiva, valoriza-se os métodos de ensino eficazes, que estimulem a participação ativa e a iniciativa dos estudantes; métodos que favoreçam 0 diálogo entre professor e estudante, levando em conta do diálogo com a cultura acumulada historicamente. Devem-se se respeitados os interesses dos alunos, seus ritmos de aprendizagem e desenvolvimento psicológico, sem perder de vista o conhecimento sistematizado.

Professores e estudantes não são reconhecidos somente em termos individuais, mas como agentes sociais. Isso significa reconhecê-los como produtos da sociedade e atores sociais. O ponto de partida do ensino seria a prática social, da qual tanto docente quanto discentes são participantes e a respeito da qual podem se posicionar de formas distintas. Nesse sentido, ao tratar do tema "energia" seria conveniente que se tomasse a produção da energia elétrica na perspectiva da prática social para que, a partir daí, pudesse se problematizar o tema, discutir os instrumentos teóricos relacionados, incorporar à discussão inicial os novos elementos, parte da totalidade do conhecimento social, e, enfim, retornar à prática social, agora enriquecida. Nas palavras de Saviani (2012): "Trata-se da efetiva incorporação dos instrumentos culturais, transformados agora em elementos ativos da transformação social" (p.72).

Todavia, o tema a partir do qual poderia se catalisar a discussão sobre a prática social referente à temática da energia - a produção de energia elétrica - tem seu potencial transformador ignorado: pelo lugar periférico que assume no texto (subseção "Saiba mais"); por seu conteúdo, que escamoteia sua relação contraditória com a sociedade; pela forma extremamente resumida através da 
qual o tema é apresentado, com uso parco de ilustrações, dificultando sua compreensão.

Essa ausência da sociedade nas discussões do livro cumpre bem os objetivos elencados no início de cada unidade. A partir da análise desses objetivos, concluímos que se centram na aprendizagem dos conteúdos disciplinares, sem contemplar sua relação com a sociedade.

\section{- Conteúdo genérico para um aluno abstrato}

O trabalho de Fávero e Santos (2011) consiste na análise da Coleção Cadernos da EJA, um conjunto de materiais pedagógicos destinados ao $1^{\circ}$ e $2^{\circ}$ segmentos do ensino fundamental de jovens e adultos, lançado em 2007. A coleção traz em sua materialidade as consciências envolvidas no seu processo de elaboração, vinculadas aos autores da pedagogia crítica, como Paulo Freire; aos pesquisadores da EJA; e aos professores que trabalham diretamente com os estudantes da EJA. O diálogo entre essas múltiplas consciências possibilitou a construção de um material didático orientado pelo trabalho e diálogo como princípios educativos, levando em conta a EJA em suas especificidades históricas e sociais. O que encontramos no material didático do Nova EJA?

Sabendo da importância do trabalho, no sentido de emprego, para o aluno da EJA, é de se esperar que o tema tenha alguma pertinência, ao menos em termos de contextualização dos conteúdos físicos. Observamos que a palavra "trabalho" aparece apenas em três trechos. Em dois deles (Rio de Janeiro, 2013a, p. 188, 192) serve para designação de lugar (logo poderia ser substituída por praça, rua etc.); no último, a palavra tem sentido de atividade laboral (Ibid., p. 241). Para além da palavra em si, a leitura do material didático aponta para a desconsideração da temática do trabalho no processo de ensino e aprendizagem dos conteúdos de Física para os sujeitos da EJA. O importante para os autores é apresentar o conteúdo físico por si só, asséptico dos contextos de vida dos estudantes, independente de suas vidas concretas. 
Gramsci (2014) afirma a importância da "participação realmente ativa do aluno na escola, que só pode existir se a escola for ligada à vida" (p.46). É fundamental que, na educação escolar, se leve em conta os saberes trazidos pelos alunos, de se articular as experiências com e no mundo do trabalho às práticas escolares, ou ainda contemplar os saberes demandados e produzidos por suas atividades profissionais. É dessa forma que se possibilita a superação da dualidade entre trabalho manual e intelectual, bem como o desenvolvimento de uma educação escolar que leve em conta o sujeito em sua integralidade.

Vale destacar que, dentro dos limites dessa pesquisa e de nossa experiência na rede estadual, desconhecemos a participação dos docentes e pesquisadores da EJA na elaboração do material didático que se pretende específico para essa modalidade.

Um professor entrevistado assinala a dificuldade de se desenvolver a "criticidade" (capacidade de questionamento, segundo o docente) a partir do material do aluno, por conta da abordagem predominante "mecanicista":

[...] nós não podemos deixar de lembrar que o livro tá imbuído em um contexto em que a gente passou durante anos fazendo exercícios de Física a la Ramalho, Nicolau, Toledo; a la Fuke Kazuito Carlos; extremamente mecanicistas (...) O livro tem exercícios de caráter mecanicista também, resolução de problemas básicos. Dá a fórmula você resolve, dá a equação e você molda. Entendeu?

O conteudismo dominante no livro do estudante do NEJA indica a intenção de se apresentar um material válido para qualquer pessoa, contexto e época interessante notar que as edições impressas não possuem data ou informações de catalogação, que podem indicar simultaneamente a intenção de ser genericamente válido a todos os contextos e o desleixo da edição. Não há indicativos de que professores da EJA tenham sido ouvidos no processo de confecção do material didático. Inclusive, na formação continuada obrigatória da qual participamos não nos foi solicitado uma avaliação ou sugestões a respeito do material do professor e do aluno. O que conta é o conteúdo de Física descolado de sua realidade histórico-social de produção, afastado de sua 
relação com a sociedade contemporânea, sob o profundo silêncio dos sujeitos a que se destina. Sujeitos prejudicados em seu direito à educação de qualidade por um material que os trata como tábula rasa - como se nada pudessem trazer ao processo educativo - e vazios histórico-sociais.

Somado a isso, vale se questionar: quais sentidos sobre o ensino de Física para a EJA emergem das entrevistas? Notamos que a importância da Física está relacionada a objetivos "um pouco mais concretos", em específico a melhoria da posição no mercado de trabalho, e ainda pode ser relevante na compreensão de atividades e situações no ambiente de trabalho e também no cotidiano. Todavia, percebe-se uma forte ênfase na relação entre a EJA e mercado de trabalho.

No colégio em Itaboraí, segundo um dos docentes, a maioria dos alunos ingressa na EJA tendo em vista a obtenção de certificação para galgar postos de trabalho mais atraentes e a satisfação pessoal de concluir seus estudos em nível médio. O docente ainda sinaliza que o estudo da Física pode levar o aluno a desenvolver um senso crítico, o apreço pela pesquisa, em querer saber o porquê e pela busca da verdade. Essas qualidades são vinculadas à ideia de que tais comportamentos seriam desejáveis no mercado e, por isso, poderia por o aluno numa posição mais avançada. Para o docente, desenvolver o senso crítico seria

[...] questionar exatamente se tem que ser assim, se é assim, se por que que é assim. Os porquês. Por que não pode ser de outra forma? E possível que seja de outra forma? É necessário dessa forma ou pode ser de uma outra maneira? Existe uma forma mais fácil? Fazer perguntas.

Segundo o docente, o senso crítico seria uma das habilidades e competências a ser desenvolvida na EJA. E assim ele justifica: "Porque o trabalho às vezes necessita de pessoas que possam fazer perguntas. Que consigam fazer perguntas".

No caso da escola em Itaboraí, nota-se que o início da implantação do Complexo Petroquímico do Estado do Rio de Janeiro tem motivado a busca dos alunos jovens e adultos pela conclusão do ensino médio, tendo em vista a possibilidade 
de aproveitar as novas chances relacionadas ao empreendimento ou apenas se manter no posto alcançado, obedecendo às exigências das empresas. Alunos nesse perfil compõem a maioria dos estudantes que procuram a escola.

A partir dessas observações, percebemos que o ensino de Física proporcionado é fortemente enviesado para o mercado de trabalho. Inclusive o desenvolvimento do "senso crítico" é subordinado aos interesses do mercado - subordinado, mas não necessariamente subsumido em sua totalidade.

\section{CONSIDERAÇõEs FINAIS}

No contexto brasileiro as classes dominantes não negam à população o direito à escola, tendo em vista a ampliação de acesso das últimas décadas, fruto da luta dos trabalhadores e das concessões da burguesia (Frigotto, 2010). Contudo, por pertencer ao sistema capitalista, a escola continua a servir como mediação através da qual se as classes dominantes realizam seus interesses. Um dos mecanismos que age para esse fim é a desqualificação da escola destinada aos pobres.

A desqualificação via NEJA, do ponto de vista do presente trabalho, se dá de formas diversas: na reiteração do tipo de intervenção do Estado na EJA, através de programa, em vez de uma política de Estado; na forma verticalizada que se deu a implementação do programa, sem que fossem consideradas as pesquisas na área de Educação e as contribuições dos professores da modalidade; na desconsideração da experiência do estudante jovem e adulto na elaboração do material didático e na orientação da formação continuada; nos aspectos relacionados à relação quantidade/qualidade do livro didático (a quantidade de erros de ortografia, de concordância, de organização são inaceitáveis), bem como o enfoque conteudista do material, que elide à historicidade do conhecimento físico, seus desdobramentos tecnológicos, sociais e ambientais, e à prática social do estudante da modalidade. 
Considerando o papel do Brasil no âmbito mundial, estruturalmente articulado como país capitalista dependente (Fernandes, 1981) no qual não faz sentido, do ponto de vista das classes dominantes, a preparação da ampla maioria da população ao trabalho complexo, o tom moderno dado pela SEEDUC, ao afirmar estar preocupada em "consolidar uma escola de qualidade, conectada ao século XXI, capacitada para preparar os jovens e adultos para o mercado de trabalho" (Rio de Janeiro, 2015, p.5) pode soar como mera propaganda e engodo. Afinal, a ideia do novo, do moderno muitas vezes vêm associada à expectativa de mudança e melhoria, e acaba servindo à ocultação de sua funcionalidade. Tendo o cuidado de não reproduzir uma visão simplista da história como mera repetição, qual seria a diferença do lugar destinado ao jovem e adulto trabalhador nos séculos $X X$ e XXI, na sociedade brasileira, estruturalmente marcada pela modernização do arcaico que não seja o trabalho simples e precário?

A partir das entrevistas, destacamos que o sentido produzido para a função principal do ensino de Física seria a de capacitar o aluno para o mercado de trabalho. Apesar de verificarmos outras motivações, como a de compreensão dos fenômenos naturais e tecnologias cotidianas, ficou-nos claro a centralidade da preparação para o mundo do trabalho como objetivo do ensino de Física para a modalidade. Parece haver uma relação linear entre educação e competitividade, tese do capital humano, expressão de um senso comum que elide à precarização do trabalho, ao desemprego estrutural e à alocação de ampla fração da população em postos de trabalhos flexíveis, precários e intermitentes.

Um dos objetivos do ensino de Física seria o de desenvolver o senso crítico: "questionar exatamente se tem que ser assim, se é assim, se por que que é assim". Esse tipo de questionamento, que poderia apontar para uma crítica social, é reduzido à mais uma habilidade exigida pelo mercado. Isso torna-se mais agudo na percepção de que a grande maioria dos estudantes buscam exatamente a melhoria no posto de trabalho ou sua manutenção, em especial 
numa região na qual se difunde a ideia de ampliação de possibilidades de emprego, efeito da construção do Complexo Petroquímico do Estado do Rio de Janeiro nas proximidades da escola, no município de Itaboraí.

Identificamos no campo de pesquisa a presença de docentes de outras áreas (Química e Matemática) lecionando a disciplina Física no programa Nova EJA, uma prática comum na rede estadual de ensino, tendo em vista a nossa experiência ao longo desses oito anos lecionando em escolas públicas. Notamos forte de tendência de resumir o ensino de Física à resolução de problemas matemáticos, em detrimento à conjugação da prática social dos estudantes com os conteúdos físicos. Nesse sentido, a presença de professores nãoespecialistas nos quadros do programa Nova EJA, parece reduzir o ensino de Física à resolução de problemas artificiais e pouco significativos aos estudantes, desfavorecendo a aprendizagem dos conhecimentos físicos socialmente produzidos.

Apesar de a prática docente ser emoldurada pelos objetivos do mercado, o que nos permite deduzir sérios comprometimento ao desenvolvimento ético-político dos estudantes, não podemos desconsiderar a importância da ação do professor no âmbito da transmissão do conhecimento físico e, por isso, na elevação cultural dos estudantes jovens e adultos. Julgamos que a ação do professor em sala de aula tem papel fundamental na produção de sentidos para os objetivos do ensino, dentro de determinados limites, a despeito daqueles fixados nos documentos. A relativa autonomia docente se apresenta como um elemento fundamental na disputa de sentidos para o ensino de Física para a EJA.

As possibilidades formativas do programa Nova EJA, sob a perspectiva da formação humana enquanto princípio educativo, no ensino de Física, depreendidas da presente análise, decididamente alinham-se às demandas do capital e afastam-se da formação integral do ser humano, por nós defendida. Contudo, apesar dos sentidos apreendidos para a educação e de ensino de Física, produzidos pelas consciências diversas que dão materialidade aos documentos oficiais e no material didático, a autonomia relativa do professor se 
mostra como uma rica possibilidade de produção de sentidos para o ensino de Física; e, quiçá, daqueles comprometidos com a formação integral do ser humano e de uma sociedade menos desigual.

\section{REFERÊNCIAS}

ALVARENGA, Marcia Soares de. Plano Nacional de Educação: contrapontos à forma jurídica sujeito de direito na educação de jovens e adultos. Trabalho Necessário, v. 1, p. 103-125, 2015.

BAKHTIN, Mikhail. Marxismo e filosofia da linguagem. São Paulo: HUCITEC, 2006.

BANCO MUNDIAL. Educação primária. Documento de política do Banco Mundial, Washington, D.C., 1992 apud TORRES, Rosa María. Melhorar a qualidade da educação básica? As estratégias do Banco Mundial. In: TOMMASI, Livia de; WARDE, Mirian Jorge; HADDAD, Sérgio. O Banco Mundial e as políticas educacionais. São Paulo: Cortez, p.125-193,1998.

FARIA, Ana Lúcia G. de. Ideologia no livro didático. São Paulo: Cortez, 2000.

FÁVERO, Osmar; SANTOS, Ênio Serra dos. Análise da Coleção Cadernos da EJA: materiais pedagógicos para o $1^{\circ}$ e $2^{\circ}$ segmentos do ensino fundamental de jovens e adultos. In: TIRIBA, Lia; CIAVATTA, Maria (Orgs.). Trabalho e educação de jovens e adultos. Brasília: Liber Livro e Editora UFF, 2011. p. 199-238.

FERNANDES, Florestan. Capitalismo dependente e classes sociais na América Latina. Rio de Janeiro, Zahar Editores, 1981.

FIGUEIREDO, Ireni Marilene Zago. Projetos financiados pelo banco mundial para o ensino fundamental no Brasil. Educação e Sociedade. Campinas, vol. 30, n. 109, p. 1123-1138, set./dez. 2009.

FREITAS, Carmen Cunha Rodrigues; LIMA, Leticia Bezerra de; MAGALHÃES, Ligia Karam Corrêa de; PICCINI, Claudia Lino. O empresariamento da educação pública: o caso do Programa Acelera Brasil. Germinal: Marxismo e Educação em Debate. Salvador, v.5, n.1, p. 110-121, jun. 2013.

FRIGOTTO, Gaudêncio. A interdisciplinaridade como necessidade e como problema nas ciências sociais. Ideação - Revista do Centro de Educação e Letras da UNIOESTE - Campus de Foz do Iguaçu, v.10, no 1, p.41-62, $1^{\circ}$ semestre de 2008.2 Disponível em: <http://www.gestaoescolar.diaadia.pr.gov.br/arquivos/File/sem_pedagogica/f 
ev_2014/NRE/2interdisciplinaridade_necessidade.pdf>. Acesso em: 29 março 2016.

FRIGOTTO, Gaudêncio. A produtividade da escola improdutiva: um (re)exame das relações entre educação e estrutura econômico-social capitalista. São Paulo: Cortez, 2010.

GRAMSCI, Antonio. Cadernos do cárcere. Vol. 2. Rio de janeiro: Civilização Brasileira, 2014.

HÖFFLING, Eloísa de Mattos. Estado e políticas (públicas) sociais. Cadernos Cedes, v. 21, n. 55, p. 30-41, 2001.

KOSIK, Karel. Dialética do Concreto. 2.ed. Rio de Janeiro: Paz e Terra, 1976.

LEFEBVRE, Henri. Marxismo. Porto Alegre: L\&PM, 2013.

LIBÂNEO, José Carlos. Democratização da escola pública: a pedagogia crítico-social dos conteúdos. São Paulo: Edições Loyola, 2012.

MACHADO, Maria Margarida. Educação de jovens e adultos: relação educação e trabalho. Retratos da Escola, v. 7, p. 373-385, 2013.

OLIVEIRA, Francisco de. Crítica à razão dualista: o ornitorrinco. São Paulo: Boitempo, 2003.

PAULANI, Leda Maria. O Projeto Neoliberal para a Sociedade Brasileira: sua dinâmica e seus impasses. In: LIMA, Júlio César França; NEVES, Lúcia Maria Wanderley (Orgs.). Fundamentos da Educação Escolar no Brasil Contemporâneo. Rio de Janeiro: Editora Fiocruz/EPSJV, 2006. p. 69-108.

RAMOS, Marise Nogueira. A Pedagogia das Competências: Autonomia ou Adaptação? São Paulo: Cortez, 2002.

RIO DE JANEIRO (RJ). Resolução SEEDUC № 4951 de 04 de outubro de 2013. Diário Oficial do Estado do Rio de Janeiro. Rio de Janeiro, RJ, 8 out. 2013, p. 25. Disponível em: <http://www.jusbrasil.com.br/diarios/60068009/doerjpoder-executivo-08-10-2013-pg-25/pdfView>. Acesso em: 28 março 2016.

Secretaria de Estado de Educação. Ciências da Natureza e suas Tecnologias. Módulo 2, Volume 1, Biologia, Química e Física. Rio de Janeiro: Fundação CECIERJ, 2013a. Disponível em: <http://projetoseeduc.cecierj.edu.br/eja/material-aluno/modulo02/Ciencias_Natureza_Nova_Eja_Aluno_Mod02_Vol01.pdf>. Acesso: 20 março 2016.

. Secretaria de Estado de Educação. Ciências da Natureza e suas Tecnologias. Módulo 2, Volume 2, Biologia, Química e Física. Rio de Janeiro: Fundação CECIERJ, 2013b. Disponível em: $<$ http://projetoseeduc.cecierj.edu.br/eja/material-aluno/modulo02/Ciencias_Natureza_Nova_Eja_Aluno_Mod02_Vol02.pdf>.

Secretaria de Estado de Educação. Ciências da Natureza e suas Tecnologias. Módulo 4, Volume 1, Biologia, Química e Física. Rio de Janeiro: Fundação CECIERJ, 2013c. Disponível em: 
$<$ http://projetoseeduc.cecierj.edu.br/eja/material-aluno/modulo02/Ciencias_Natureza_Nova_Eja_Aluno_Mod04_Vol01.pdf>.

Secretaria de Estado de Educação. Ciências da Natureza e suas Tecnologias. Módulo 4, Volume 2, Biologia, Química e Física. Rio de Janeiro: Fundação CECIERJ, 2013d. Disponível em: $<$ http://projetoseeduc.cecierj.edu.br/eja/material-aluno/modulo02/Ciencias_Natureza_Nova_Eja_Aluno_Mod04_Vol02.pdf>. Acesso: 20 março 2016.

. Secretaria de Estado de Educação. Relatório de Gestão e Políticas Públicas 2014 - parte 1, 2014a. Disponível em: <http://download.rj.gov.br/documentos/10112/2247397/DLFE72622.pdf/RGPP2014Parte1.pdf>. Acesso em: 28 março 2016.

Secretaria de Estado de Educação. Relatório de Gestão e Políticas Públicas 2014 - parte 2, 2014b. Disponível em: <http://download.rj.gov.br/documentos/10112/2247397/DLFE72623.pdf/RGPP2014Parte2.pdf>. Acesso em: 28 março 2016.

Secretaria de Estado de Educação. Manual de orientações Nova EJA, 2015. Disponível em: <http://projetoseeduc.cecierj.edu.br/eja/manualeja.pdf>. Acesso em: 28 março 2015.

RUMMERT, Sonia Maria. A educação de jovens e adultos trabalhadores brasileiros no século XXI. O "novo" que reitera antiga destituição de direitos. Sísifo. Revista de Ciências da Educação, № 2, p. 35-50, jan/abr 2007.

SAVIANI, Dermeval. Pedagogia histórico-crítica: primeiras aproximações. Campinas, SP: Autores Associados, 2011.

SAVIANI, Dermeval. Escola e democracia. Campinas, SP: Autores Associados, 2012.

SAVIANI, Dermeval; DUARTE, Newton. A formação humana na perspectiva histórico-ontológica. Revista Brasileira de Educação, v. 15, n. 45, p. $422-$ 433, 2010.

SHIROMA, Eneida Oto; MORARES, Maria Célia Marcondes de; EVANGELISTA, Olinda. Política Educacional. Rio de Janeiro: Lamparina. 2011.

SOUZA, Adriéli Cristina de; BUENO, Cristiane Aparecida Ribeiro; FIGUEIREDO, Ireni Marilene Zago. Alternativas para melhorar o fluxo escolar no ensino fundamental: promoção automática e correção da defasagem idade-série. Cadernos de Educação, n. 39, 2011.

TORRES, Rosa María. Melhorar a qualidade da educação básica? As estratégias do Banco Mundial. In: TOMMASI, Livia de; WARDE, Mirian Jorge; HADDAD, Sérgio. O Banco Mundial e as políticas educacionais. São Paulo: Cortez, 1998. p.125-193. 